\title{
Selective Glial Cell Line-Derived Neurotrophic Factor Production in Adult Dopaminergic Carotid Body Cells In Situ and after Intrastriatal Transplantation
}

\author{
Javier Villadiego, ${ }^{1}$ Simón Méndez-Ferrer, ${ }^{1}$ Teresa Valdés-Sánchez, ${ }^{2}$ Inmaculada Silos-Santiago, ${ }^{1}$ Isabel Fariñas, ${ }^{2}$ \\ José López-Barneo, ${ }^{1}$ and Juan J. Toledo-Aral ${ }^{1}$ \\ ${ }^{1}$ Laboratorio de Investigaciones Biomédicas, Departamento de Fisiología and Hospital Universitario Virgen del Rocío, Universidad de Sevilla, 41013 Sevilla, \\ Spain, and ${ }^{2}$ Departamento de Biología Celular, Universidad de Valencia, 46100 Burjassot, Spain
}

Glial cell line-derived neurotrophic factor (GDNF) exerts a notable protective effect on dopaminergic neurons in rodent and primate models of Parkinson's disease (PD). The clinical applicability of this therapy is, however, hampered by the need of a durable and stable GDNF source allowing the safe and continuous delivery of the trophic factor into the brain parenchyma. Intrastriatal carotid body (CB) autografting is a neuroprotective therapy potentially useful in PD. It induces long-term recovery of parkinsonian animals through a trophic effect on nigrostriatal neurons and causes amelioration of symptoms in some PD patients. Moreover, the adult rodent CB has been shown to express GDNF. Here we show, using heterozygous GDNF/lacZ knock-out mice, that unexpectedly CB dopaminergic glomus, or type I, cells are the source of CB GDNF. Among the neural or paraneural cells tested, glomus cells are those that synthesize and release the highest amount of GDNF in the adult rodent (as measured by standard and in situ ELISA). Furthermore, GDNF expression by glomus cells is maintained after intrastriatal grafting and in CB of aged and parkinsonian 1-methyl-4-phenyl-1,2,3,6-tetrahydropyridine-treated animals. Thus, glomus cells appear to be prototypical abundant sources of GDNF, ideally suited to be used as biological pumps for the endogenous delivery of trophic factors in PD and other neurodegenerative diseases.

Key words: GDNF expression; glomus cells; carotid body; intrastriatal transplants; parkinsonian models; GDNF knock-out mice

\section{Introduction}

Neurotrophic factors have emerged recently as promising therapeutic tools for neurodegenerative disorders because they can prevent neuronal death. The impairment of motor functions characteristic of Parkinson's disease (PD) results primarily from the progressive degeneration of dopaminergic neurons in the substantia nigra ( $\mathrm{SN}$ ) projecting to the striatum. Thus, in parallel with work focused on transplantation of dopamine-secreting cells, several studies have promoted the use of the dopaminotrophic glial cell line-derived neurotrophic factor (GDNF) (Lin et al., 1993) to treat PD. In rodent and primate models of PD, GDNF has been shown to be neuroprotective and to induce fiber outgrowth when administered into the ventricles or directly into the brain parenchyma (Tomac et al., 1995; Gash et al., 1996; Björklund et al., 1997; Choi-Lundberg et al., 1997; Rosenblad et

\footnotetext{
Received 0ct. 17, 2004; revised Feb. 18, 2005; accepted March 11, 2005.

This work was supported by grants from the Spanish Ministry of Education and Science (Genómica y Proteómica and SAF programs), the Spanish Ministry of Health (Redes (entro de Investigación de Enfermedades Neurológicas and Terapia (elular), and the Andalusian Government and Foundations Lilly, Areces, and La (aixa. J. L.-B. received the "Ayuda a la Investigación 2000" of the Juan March Foundation. We thank Dr. Espejo for the help extracting the Zuckerkandl's organ. J.V. and S.M.-F. received predoctoral fellowships of the Spanish Government.

Correspondence should be addressed to Dr. Juan José Toledo-Aral, Laboratorio de Investigaciones Biomédicas, Edificio de Laboratorios, Segunda Planta, Hospital Universitario Virgen del Rocío, Avenida Manuel Siurot $s / n$ E-41013 Sevilla, Spain. E-mail: juanjo@us.es.

I. Silos-Santiago's present address: Department of Pharmacology, Vertex Pharmaceuticals, San Diego, CA 92121. DOI:10.1523/JNEUROSCI.4312-04.2005

Copyright $\odot 2005$ Society for Neuroscience $\quad$ 0270-6474/05/254091-08\$15.00/0
}

al., 1998; Kordower et al., 2000; Akerud et al., 2001; Grondin et al., 2002). The applicability of GDNF therapy to PD patients is being assayed in clinical trails, and the method of delivery has become a critical issue (Gill et al., 2003; Nutt et al., 2003; Kirik et al., 2004). The variables that determine the efficacy of GDNF to ameliorate PD in animal models and humans remain unclear.

The use of carotid body (CB) tissue to treat PD has been suggested because it is composed of glomus cells, which contain and secrete high levels of dopamine and, in addition, are resistant to hypoxia (Lopez-Barneo et al., 2001). Intrastriatal transplantation of CB cells has been shown to produce a marked amelioration of experimental parkinsonism in rodents (Espejo et al., 1998; Hao et al., 2002; Toledo-Aral et al., 2003; Shuukla et al., 2004) and monkeys (Luquin et al., 1999). A recent safety study has shown that $\mathrm{CB}$ autografts can induce significant beneficial clinical effects on PD patients (Arjona et al., 2003). Observations in rodents have, however, indicated that CB transplants improve parkinsonian symptoms because of a trophic effect on the nigrostriatal neurons, which are encouraged to reinnervate the striatum, rather than because of the release of dopamine from the transplanted cells. These experiments have also demonstrated that GDNF is expressed in the CB of adult mice (Toledo-Aral et al., 2003).

The present research was undertaken to identify the source of GDNF produced in the CB and to estimate the level of GDNF synthesized in the $\mathrm{CB}$ compared with other neural or paraneural tissues previously or currently used for transplantation studies in 
PD. We also examined whether GDNF production is maintained after intrastriatal $\mathrm{CB}$ grafting and in $\mathrm{CB}$ of aged and parkinsonian [1-methyl-4-phenyl-1,2,3,6-tetrahydropyridine (MPTP)-treated] animals. Finally, we investigated whether nonspecific sources of GDNF are activated after brain injury produced by the transplantation surgery. We show that CB GDNF is produced in dopaminergic glomus cells. Among the cells tested, glomus cells are those with the higher capacity to produce and secrete GDNF in the adult rodent, maintaining a stable phenotype once they are transplanted in the striatum. Glomus cells appear to be an ideal prototypical device for the synergistic endogenous delivery of GDNF and other trophic factors in the brain parenchyma.

\section{Materials and Methods}

Animal care and chronic MPTP treatment. Heterozygous GDNF/lacZ mice (Sánchez et al., 1996), C57BL/6 mice and Wistar rats were housed at a regulated temperature $\left(22 \pm 1^{\circ} \mathrm{C}\right)$ in a $12 \mathrm{~h}$ light/dark cycle, with access ad libitum to food and water. Animal surgery and killing were performed under chloral hydrate anesthesia $(490 \mathrm{mg} / \mathrm{kg}$ for mice and $350 \mathrm{mg} / \mathrm{kg}$ for rats, i.p.). Heterozygous GDNF/lacZ mice (2 months old) were rendered parkinsonian by the subcutaneous administration $(20 \mathrm{mg} / \mathrm{kg})$ of MPTP (Sigma, St. Louis, MO) twice per week during 3 months. All experiments were performed according to the animal care guidelines of the European Communities Council (86/609/EEC). The study was approved by the Committee on Animal Research at the University of Seville, University Hospital Virgen del Rocío.

Histological analyses. Mouse tissues were removed from anesthetized animals and immediately fixed overnight at $4{ }^{\circ} \mathrm{C}$ with $4 \%$ paraformaldehyde in PBS. Slices 40-100 $\mu \mathrm{m}$ thick were cut with a Vibratome (Vibratome, St. Louis, MO). Tyrosine hydroxylase (TH) immunohistological detection was as described previously (Toledo-Aral et al., 2003), using a polyclonal anti-TH antibody (1:1000; Pel-Freez, Roger, AR) and a secondary biotin conjugated anti-rabbit antibody (1:200; Pierce, Rockport, IL). For the histological detection of GDNF expression, we used heterozygous GDNF/lacZ mice 1-17.5 months old and the 5-bromo-4chloro-3-indolyl- $\beta$-D-galactopyranoside (X-gal) staining (Sánchez et al., 1996). For colocalization studies, TH immunohistochemistry was performed after X-gal staining. Quantification of GDNF expression in CBs of aged, MPTP-treated, and control heterozygous GDNF/lacZ mice was done by counting the total number of blue-green $\mathrm{X}$-gal dots. For that purpose, all of the $\mathrm{CB}$-containing slices were photographed and digitized in series changing the focal plane in $8 \mu \mathrm{m}$ steps. CB volume was calculated from the thickness of the CB-containing slices, and the $\mathrm{CB}$ area in each section was obtained by computer using the appropriate tools of Canvas 6.0 (Deneba Systems, Miami, FL). MPTP-induced neuronal damage in heterozygous GDNF/lacZ mice was roughly estimated by counting TH-positive cells of the substantia nigra in mesencephalic coronal sections (10 per animal). This value was compared with the one obtained using the same procedure in control (saline-injected) animals. Values are given as mean \pm SEM. The statistical significance of differences among parameters was considered at a value of $p<0.05$ (Student's $t$ test).

Immunocytochemistry in mice carotid body primary cell cultures. CBs were removed from carotid bifurcations of heterozygous GDNF/lacZ mice (4-6 weeks old). Immediately thereafter, the CBs were dissected in Tyrode's solution at $4^{\circ} \mathrm{C}$ with oxygen saturation. $\mathrm{CBs}$ were then incubated in Tyrode's solution containing $0.6 \mathrm{mg} / \mathrm{ml}$ collagenase type II (Sigma) and $0.3 \mathrm{mg} / \mathrm{ml}$ trypsin (Sigma) for $30 \mathrm{~min}$ at $37^{\circ} \mathrm{C}$ with shaking and mechanic disruption every 10 min using fire-polished Pasteur pipettes. After the enzymatic treatment, dissociated CB cells were centrifuged for $5 \mathrm{~min}$ at $200 \times \mathrm{g}$ and $4^{\circ} \mathrm{C}$. Afterward, the pellet was resuspended in DMEM (Invitrogen, Grand Island, NY) supplemented with 10\% fetal bovine serum (BioWhittaker, Verviers, Belgium), 1\% penicillin/streptomycin (BioWhittaker), 1\% L-glutamine (BioWhittaker), and $0.085 \mathrm{U} / \mathrm{ml}$ insulin (Novo Nordisk, Bagsvaerd, Denmark). Finally, CB cells were plated on glass coverslips previously coated with collagen (Sigma) and 1 $\mathrm{mg} / \mathrm{ml}$ poly-L-lysine (Sigma) and cultured at $37^{\circ} \mathrm{C}$ in a $5 \% \mathrm{CO}_{2}$ incubator for 24 or $48 \mathrm{~h}$. The culture was fixed with 3\% paraformaldehyde in PBS before the X-gal staining. Subsequently, the immunofluorescence study was made using a polyclonal anti-TH (1:1000; Pel-Freez) and a monoclonal anti-glial fibrillary acid protein $(1: 300$; Sigma) as primary antibodies and an anti-rabbit IgG (Alexa 568, 1:700; Molecular Probes, Eugene $\mathrm{OR}$ ) and an anti-mouse fluorescein-conjugated IgG (1:200; Pierce, Rockford, IL) as secondary antibodies.

Carotid body grafting. The general procedure used for intrastriatal CB grafting in mice was similar to that described previously for rats (ToledoAral et al., 2003). Briefly, CBs were trimmed into pieces approximately half of the size of the whole organ. Usually two CB pieces were placed on $1 \mu \mathrm{l}$ of Tyrode's solution and injected into the striatum (stereotaxic coordinates referenced to bregma, in $\mathrm{mm}$ : anteroposterior, +0.4 ; lateral, +2 ; ventral, -3.5 ). Sham-operated animals received $1 \mu$ l of Tyrode's solution at the same stereotaxic coordinates.

Electron microscopy. For the electron microscopy study, heterozygous GDNF/lacZ mice carotid bifurcations and C57BL/6 mice brains grafted with CBs from heterozygous GDNF/lacZ mice were used. The extraction, fixation, sectioning, and X-gal staining of the tissue were as described above (Histological analyses). $\beta$-Galactosidase-reacted 100 - $\mu \mathrm{m}$-thick vibratome sections were fixed overnight with $0.02 \%$ glutaraldehyde and $4 \%$ paraformaldehyde in PBS and washed several times in PBS. Sections were thereafter postfixed with $1 \%$ osmium tetroxide and $7 \%$ glucose in PBS for $1 \mathrm{~h}$ at room temperature, dehydrated in ascending grades of ethanol, and flat embedded in Araldite resin (Durkupan; Fluka, NeuUlm, Germany) between two acetate sheets. Plastic-embedded sections were examined with the light microscope, and areas of interest were excised with a razor blade and glued to an empty Araldite block for sectioning at $1.5 \mu \mathrm{m}$ in a Reichert Ultracut E ultramicrotome (Leica, Deerfield, IL). These semithin sections were stained with $1 \%$ toluidine blue and examined in the light microscope, and those containing blue precipitates characteristic of the $\beta$-galactosidase reaction were selected for additional analysis and photographed. Selected semithin sections were transferred to a resin block and resectioned at 65-70 $\mathrm{nm}$ (DeFelipe and Fairén, 1982). The thin sections were collected on Formvar-coated slot grids, stained with uranyl acetate and lead citrate, and examined with a Jeol (Peabody, MA) JEM-1010 electron microscope.

GDNF ELISA. Tissue GDNF protein content was estimated in samples obtained from Wistar rats (5-20 weeks old) using a commercial ELISA kit (GDNF Emax Immunoassay System; Promega, Madison, WI). All of the tissues were removed and immediately frozen in liquid nitrogen; afterward, the samples were homogenized using a Polytron (OMNI, Waterbury, CT). For these studies, we pooled tissues removed from different animals. The total number of samples were as follows: $143 \mathrm{CBs}, 14$ adrenal medullas (AMs), 12 superior cervical ganglia (SCGs), and 3 Zuckerkandl's organs. The protein extraction and the ELISA were completed following the instructions of the manufacturer, except that the dilutions used of the anti-GDNF monoclonal and anti-hGDNF polyclonal antibodies were 1:500 and 1:250, respectively. Absorbance at 450 $\mathrm{nm}$ was measured in a plate reader (Thermo Electron Corporation, Vantaa, Finland). A separate procedure was followed to measure the release of GDNF from dissociated CB, adrenal medulla, and pheochromocytoma rat PC12 cells. Primary culture of dissociated Wistar rat [postnatal day 10 (P10) to P13] CB cells was performed as described above for mice but without insulin. Dispersed chromaffin cells were also obtained from adrenal glands of Wistar rats (P10-P13) that, after removal, were minced with standard razor blades. The pieces of adrenal glands were placed in extraction solution (in mM: $154 \mathrm{NaCl}, 5.6 \mathrm{KCl}, 11$ glucose, and 10 HEPES, pH 7.4) with $0.6 \mathrm{mg} / \mathrm{ml}$ collagenase type IA (Sigma) and 1.3 $\mathrm{mg} / \mathrm{ml}$ bovine serum albumin (Sigma) and incubated at $37^{\circ} \mathrm{C}$ for $30 \mathrm{~min}$ with mechanical dispersion every $10 \mathrm{~min}$. After dissociation, the cell suspension was centrifuged at $200 \times g$ at $4^{\circ} \mathrm{C}$ for $5 \mathrm{~min}$. The supernatant was removed, and the pellet was resuspended in PBS containing 0.6 $\mathrm{mg} / \mathrm{ml}$ collagenase type IA (Sigma) and $0.3 \mathrm{mg} / \mathrm{ml}$ trypsin (Sigma) and incubated at $37^{\circ} \mathrm{C}$ for $10 \mathrm{~min}$. Enzymes were washed with a solution containing 2 vol of DMEM (Invitrogen), 10\% fetal bovine serum (BioWhittaker), $1 \%$ penicillin/streptomycin (BioWhittaker), and $1 \%$ L-glutamine (BioWhittaker). After washing the enzymatic solution, the cells were plated using the same media. PC12 cells were cultured as described by Toledo-Aral et al. (1995). The release of GDNF from the cellular preparations was measured by a modification of the ELISA in situ 

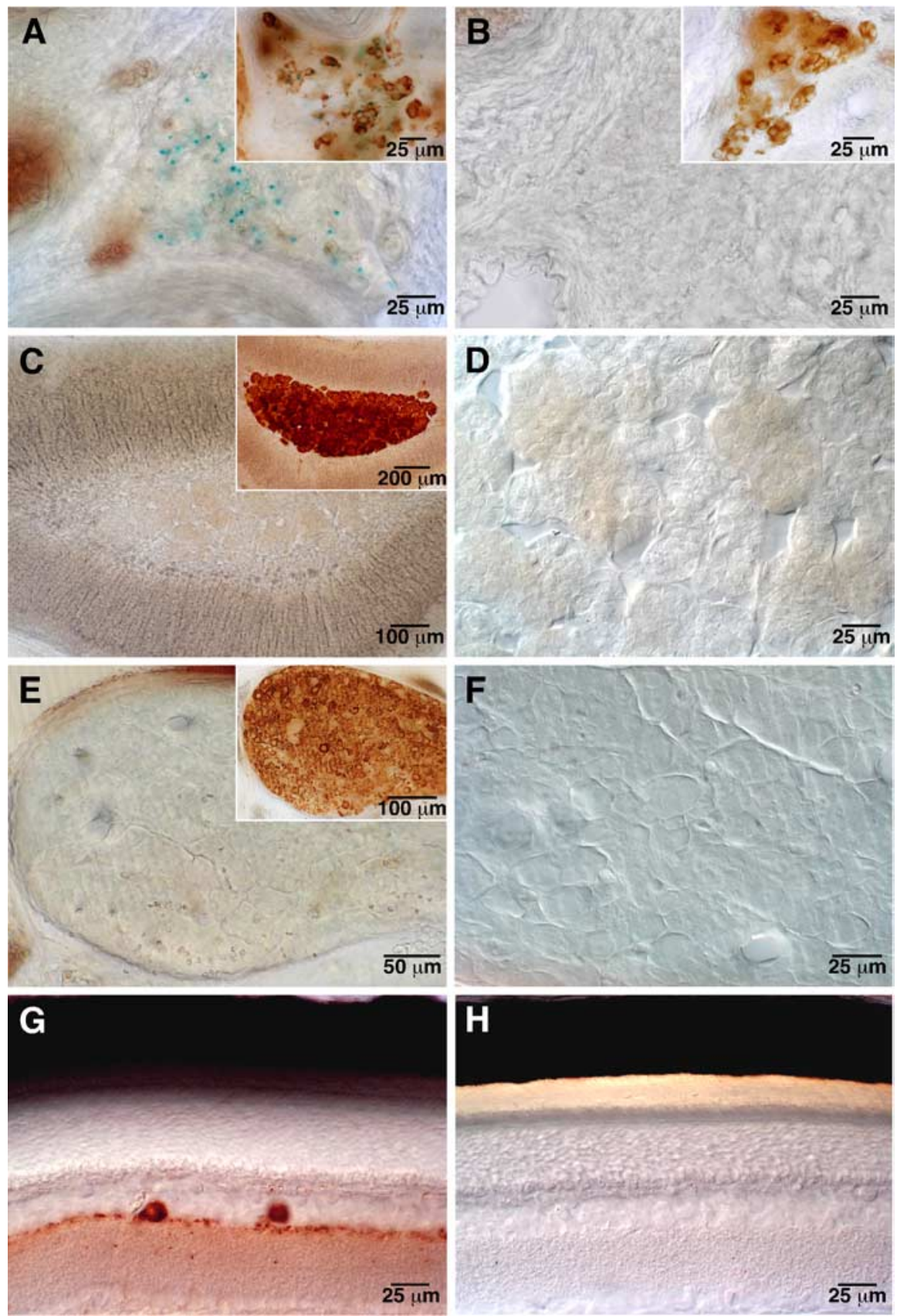

Figure 1. Selective GDNF expression in adult carotid body. $A$, GDNF expression in the carotid body (blue-green dots) evidenced by X-gal staining in heterozygous GDNF/lacZ mice (17.5 months old). The inset shows the typical glomerular structure of the CB after TH immunohistological staining. $B$, CB section from a wild-type animal with complete absence of X-gal labeling after staining ( 8.5 months of age). The inset shows again the typical glomerular structure of the same CB. $\boldsymbol{C}-\boldsymbol{H}$, Lack of GDNF expression in the adrenal medulla ( $\boldsymbol{C}, \boldsymbol{D} ; 5$ months of age), superior cervical ganglion $(\boldsymbol{E}, \boldsymbol{F} ; 5$ months of age), and retina ( $\boldsymbol{G}, \boldsymbol{H} ; \mathbf{7}$ months of age) of heterozygous GDNF/lacZ mice after X-gal staining. To confirm the stability of the tissues, the insets in $\boldsymbol{C}, \boldsymbol{E}$, and $\boldsymbol{G}$ show, respectively, the characteristic TH-positive immunostaining of adrenal medulla chromaffin cells, superior cervical ganglion neurons, and retinal amacrine cells of the same mice.

method described previously for BDNF detection (Balkowiec and Katz, 2000). Briefly, 96-well ELISA plates were UV sterilized for $30 \mathrm{~min}$ and coated with an anti-GDNF monoclonal antibody (Promega) overnight at $4^{\circ} \mathrm{C}$. The plates were washed and blocked, followed by two $1 \mathrm{~h}$ incubations with culture medium to remove any residue of the ELISA washing solutions. Primary cultures of $\mathrm{CB}, \mathrm{AM}$, and $\mathrm{PC} 12$ cells were placed in the pretreated plates $\left(1.2-5 \times 10^{4}\right.$ cells per well $)$ and cultured for $48 \mathrm{~h}$. GDNF samples used to generate the standard curve were diluted in culture medium and incubated in the same plates. After $48 \mathrm{~h}$ in culture, cells were washed, and the ELISA was performed as described above for the studies of tissue GDNF protein con- tent. ELISA results are given as mean \pm SEM. The statistical significance of differences among parameters was considered at a value of $p<0.05$ (Student's $t$ test).

\section{Results}

Selective expression of GDNF in CB glomus cells of adult rodents

GDNF is expressed in several tissues during development, and its presence in the embryonic and newborn CB has been reported previously (Nosrat et al., 1996; Lipton et al., 1999; Erickson et al., 2001). However, unequivocal evidence for GDNF expression in $\mathrm{CB}$ of adult rodents was obtained from heterozygous knock-out GDNF/lacZ mice, in which the cells expressing GDNF contain $\beta$-galactosidase deposits that can be labeled with the characteristic blue X-gal staining (Toledo-Aral et al., 2003). Using this experimental tool, we compared the level of GDNF expression in the CB and that in the AM, SCG, or retina, which are catecholaminergic donor tissues used in transplantation studies to treat PD in animals and humans (Bohn et al., 1987; Itakura et al., 1988; Yurek and Sladek, 1990; Rosenthal, 1998). The histological illustrations in Figure 1 clearly show the high level of GDNF expression in the $\mathrm{CB}$ (blue-green color deposits in $A$ ) and its complete absence in the $\operatorname{AM}(C, D)$, $\operatorname{SCG}(E, F)$, and retina $(G, H)$. As control, we also show the lack of $\mathrm{X}$-gal deposits in a $\mathrm{CB}$ from a wild-type animal $(B)$. Counterstaining with anti-TH antibody demonstrated the typical organization in clusters of CB glomus cells ( $A, B$, insets), the THpositive cells in the AM and SCG $(C, E$, insets), and the dopamine-containing amacrine cells of the retina $(G)$. Similar comparative histological analysis was performed in 25 animals (aged between 1 and 17.5 months) with identical results. In four newborn (P1) animals studied (two +/and two $-/-)$, GDNF expression was found to be high in the CB, absent in AM and SCG, and small in the retina (data not shown). Although these results clearly indicated that the adult $\mathrm{CB}$ expresses more GDNF that any other tissue tested, we directly measured the amount of GDNF protein in tissue extracts from adult rats (1-5 months of age) using a conventional ELISA detection method. GDNF content in CB was one order of magnitude higher than in AM, SCG, or the organ of Zuckerkandl, whose contents were barely detectable or below the level of resolution of the technique (Fig. 2A). The organ of Zuckerkandl, a tissue structurally related to the adrenal medulla, was included in the study because it has been reported recently to induce recovery caused by GDNF release when transplanted in the striatum of parkinsonian rats (Espejo et al., 2001). Besides the differences in GDNF synthesis and storage, CB cells 

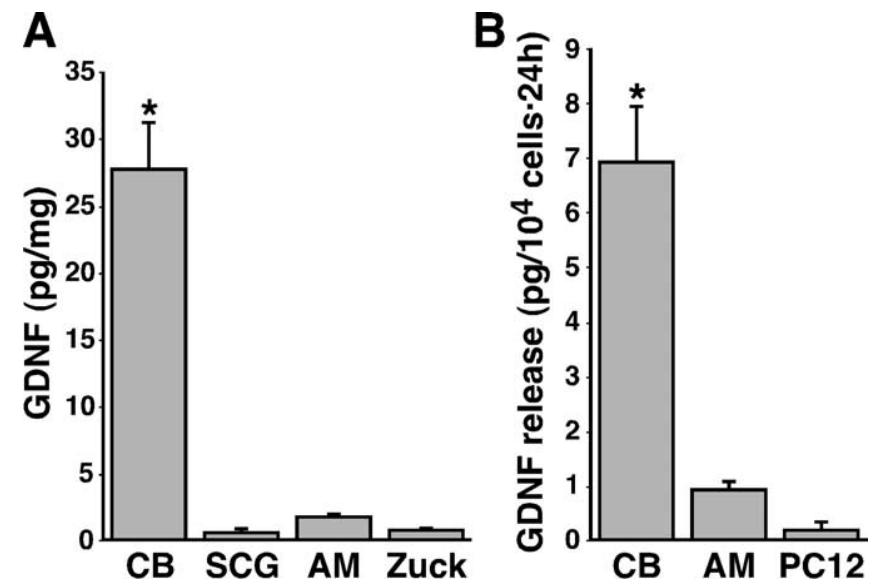

Figure 2. GDNF protein content and release in CB compared with other TH-positive preparations. $A, G D N F$ levels (in picograms per milligram) measured by standard ELISA in rat tissues. The number of separate measurements was as follows: six CBs, six SCGs, eight AMs, and three Zuckerkandl's organs (Zuck). B, GDNF release (picograms per $10^{4}$ cells in $24 \mathrm{~h}$ ) measured by the ELISA in situ assay from dispersed carotid body, adrenal medulla, and PC12 cells. Data are from six $C B$, four $A M$, and four $P(12$ different cultures in three independent experiments. The statistical significance of differences among parameters was considered at ${ }^{*} p<0.05$ (see Materials and Methods).

were also able to release more GDNF than any other cell type studied. This was demonstrated by using a highly sensitive in situ GDNF ELISA that allowed to measure GDNF secreted to the extracellular media by $\mathrm{CB}$ and other paraneural cultured cells (Fig. 2B).

To identify the source of GDNF produced in the mouse CB, the organs were enzymatically treated and cells were mechanically dispersed. The cells analyzed with the characteristic X-gal deposits $(n=151)$ were $\sim 10 \mu \mathrm{m}$ in diameter and appeared strongly stained with the anti-TH antibody but unreactive to the GFAP antibody, thus indicating that they were dopaminergic type I, or glomus, cells (Fig. $3 A-C$ ). In contrast, the subtentacular, glial-like type II cells, the second most abundant cell class in the $\mathrm{CB}$ $(n=73)$, were TH negative and GFAP positive but did not contain $\mathrm{X}$-gal inclusions (Fig. 3D-F). Electron microscopy analysis further demonstrated the presence of X-gal deposits in the cytoplasm of glomus cells, which were identified by the characteristic large nucleus with fragmented chromatin and abundant dense-core cytoplasmic secretory vesicles apposed close to the membrane (Fig. 3G$I$ ). Because GDNF was originally cloned from a glial cell line (Lin et al., 1993) and it is expressed in some glial cells in the adult brain, GDNF in the CB was thought to be expressed by subtentacular cells, thus exerting a trophic action on glomus cells (Luquin et al., 1999; Toledo-Aral et al., 2002, 2003). The results described here indicate that, unexpectedly, dopaminergic glomus cells are those responsible for the synthesis of GDNF.

\section{GDNF expression in glomus cells of intrastriatal CB grafts}

Because a major goal of this work was to evaluate the suitability of $\mathrm{CB}$ tissue for cell therapy, we tested to see whether the ability of CB cells to express GDNF is maintained after striatal transplantation. CBs from heterozygous GDNF/lacZ animals (1-2 months old) were transplanted into normal littermates (2-3 months old; $n=7$ ), and the striatum was studied $0.5-4$ months after grafting. As shown in Figure 4A, typical ovoid-shaped CB transplants with intense X-gal staining were seen in the striatum of the transplanted animals. Counterstaining with antibodies against $\mathrm{TH}$ showed that X-gal deposits were maintained in transplanted glo-
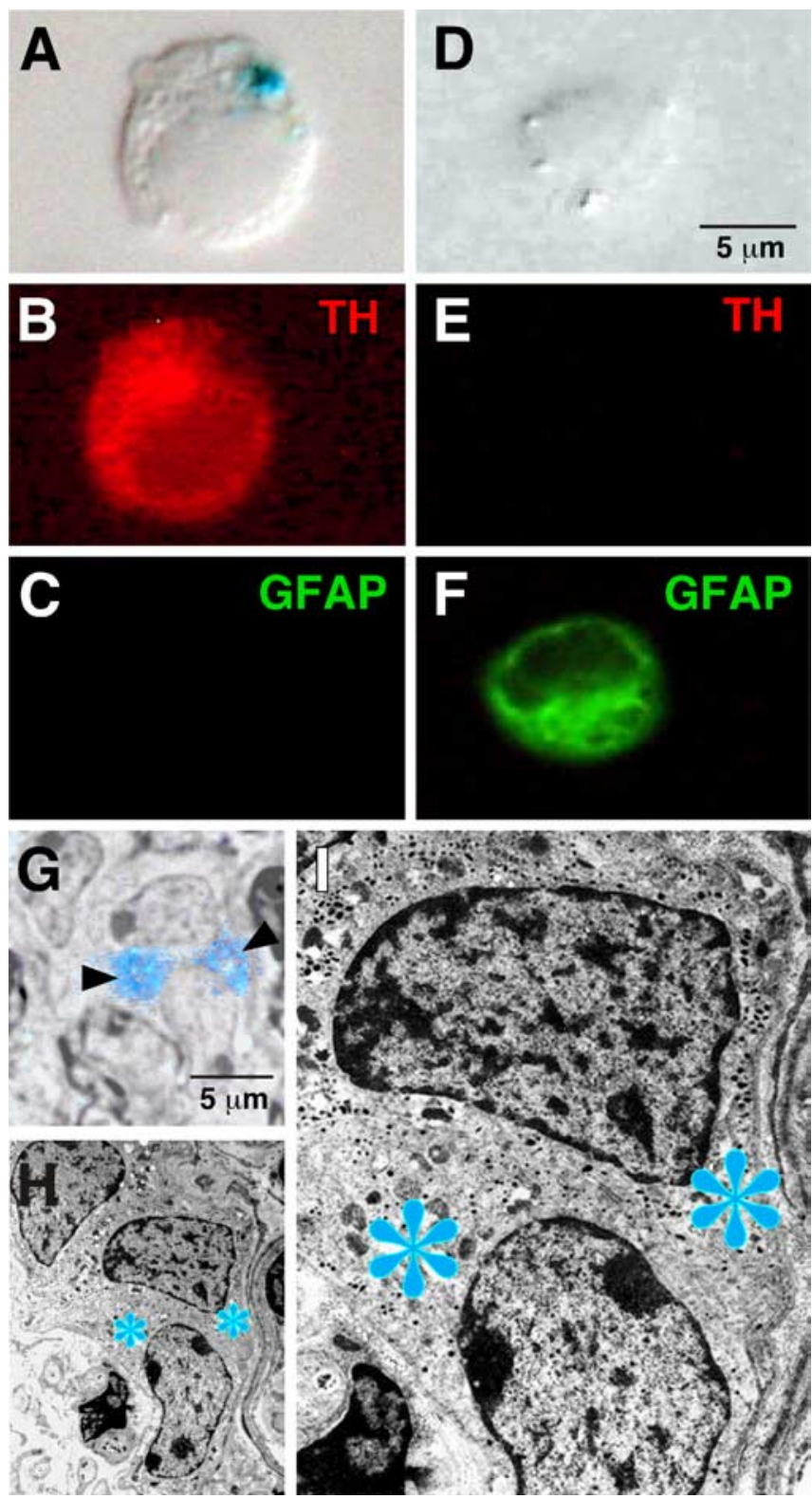

Figure 3. GDNF expression in (B glomus cells. $\boldsymbol{A}-\boldsymbol{C}, \mathrm{GDNF}$ expression (blue precipitate, $\boldsymbol{A}$ ) in a typical dispersed $C B$ glomus cell that was TH positive ( $\boldsymbol{B}$, red fluorescence) but GFAP negative (C). D-F, Lack of GDNF (D) and TH (E) expression in a representative dispersed subtentacular CB cell. Green fluorescence in $\boldsymbol{F}$ indicates that the cell was GFAP positive. The cells are examples obtained from primary cultured CB cells removed from heterozygous GDNF/lacZ mice. Cultures were subjected to $X$-gal staining and simultaneous TH and GFAP immunofluorescent detection. G-I, Ultrastructural analysis of a CB from a 6-month-old heterozygous GDNF/lacZ mouse after $\beta$-galactosidase reaction. The blue asterisks $(\boldsymbol{H}, \boldsymbol{I})$ indicate the specific localization of the $X$-gal deposits within glomus cells (see the correspondence with the blue staining indicated by arrowheads in the semithin section in $G$ ). (B glomus cells are clearly identified by the characteristic large nucleus with fragmented chromatin $(\mathbf{G}-\mathbf{I})$.

mus cells (Fig. $4 \mathrm{~B}$ ) with an appearance remarkably similar to that of the normal CB (Fig. 4C). We observed a slight increase in GDNF expression in the grafted CB cells that could be attributed to their activation by the hypoxic conditions in the brain parenchyma. Nevertheless, this phenomenon was not studied in detail. Electron microscopy analysis on CB grafts confirmed the presence of intense X-gal deposits in the cytoplasm of transplanted glomus cells, which had typically large nucleus and fragmented chromatin (Fig. 4D-F). Noticeably, the clusters of dense-core vesicles 

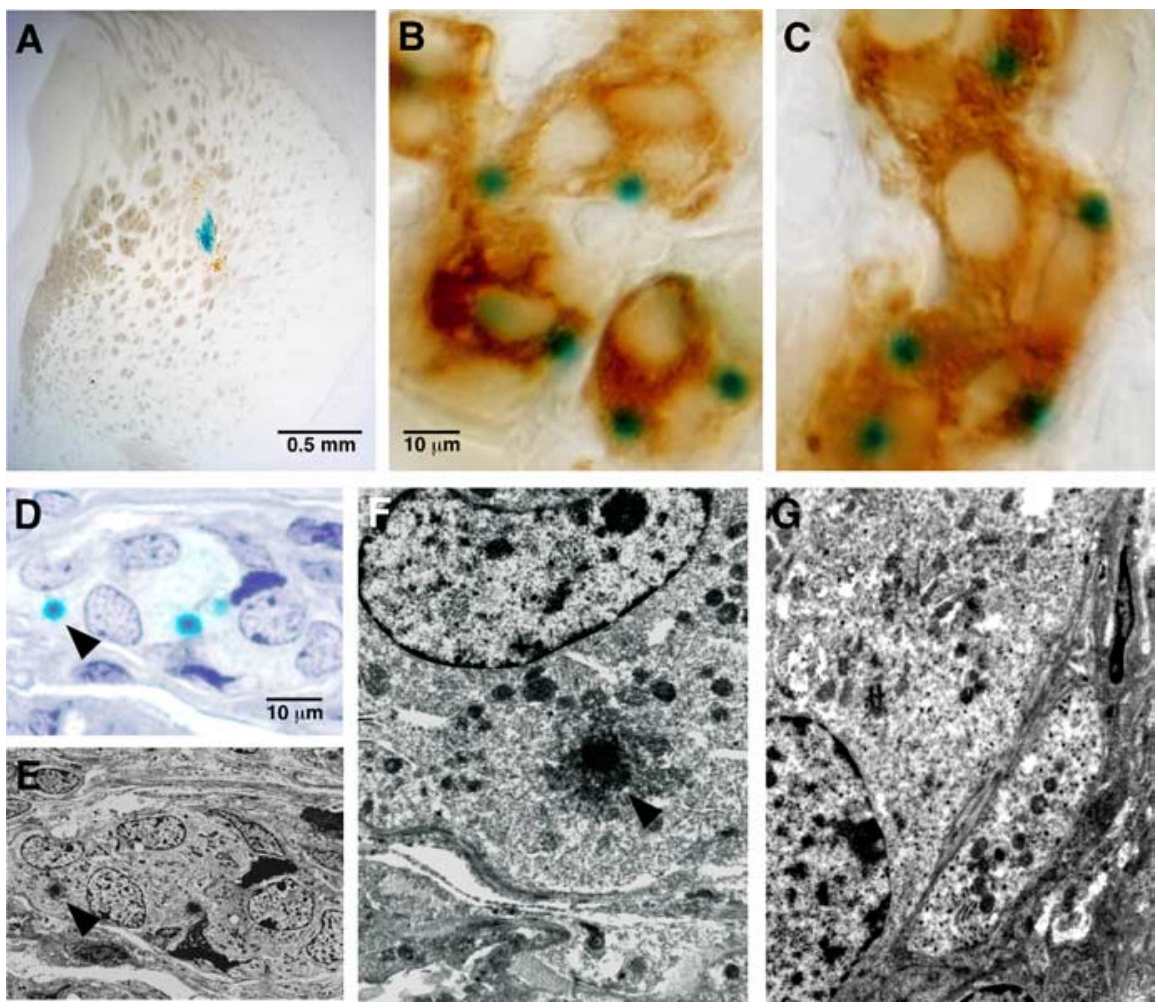

Figure 4. GDNF expression in intrastriatally grafted CB glomus cells. $\boldsymbol{A}$, GDNF expression (blue X-gal staining) in a 1 month intrastriatal CB transplant (from a 2-month-old heterozygous GDNF/lacZ mouse) grafted into a 4-month-old wild-type mouse. $\boldsymbol{B}$, C, Comparison of GDNF (green dots) and TH (light brown) expression and general phenotypic appearance of an intrastriatal CB graft ( $\boldsymbol{B} ; 1.5$ months after transplantation) and a $\mathrm{CB}$ in situ (C; removed from a 5 -month-old animal). In both cases, the tissues belong to heterozygous GDNF/lacZ mice. $\boldsymbol{D}-\boldsymbol{F}$, Ultrastructural analysis of the same CB graft shown in $\boldsymbol{A}$. The arrowhead in the semithin section $(\boldsymbol{D})$ and the pictures $(\boldsymbol{E}, \boldsymbol{F})$ indicates the correspondent $X$-gal deposit, showing the GDNF expression in grafted $C B$ glomus cells. G, Ultrastructural analysis of a 15-d-old graft showing a typical CB glomus cell with some dense-core vesicles that are dispersed throughout the cytoplasm. CB glomus cells in $\mathbf{D}-\mathbf{G}$ are clearly identified by the characteristic large nucleus with fragmented chromatin.
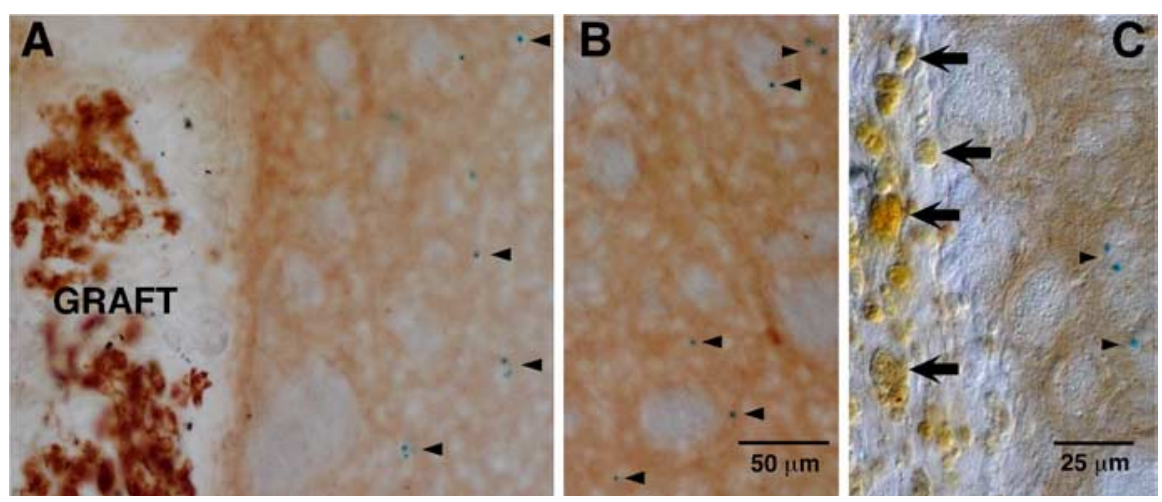

Figure 5. Absence of endogenous striatal GDNF induction by $C B$ grafting or nonspecific brain damage. $A, B$, Heterozygous GDNF/lacZ mice striatal sections ipsilateral $(\boldsymbol{A})$ and contralateral $(\boldsymbol{B})$ to a CB graft from a 1-month-old wild-type donor. Arrowheads indicate the presence of X-gal deposits (GDNF expression) in the host tissue, which was similar in the two sides of the brain. C, Heterozygous GDNF/lacZ mice striatal section of a sham-operated animal. Note the absence of X-gal deposits (indicating the lack of GDNF expression) within the bright yellowish macrophages (arrows) along the needle tract. However, X-gal deposits are clearly seen in the neighboring parenchyma. TH immunohistochemistry was performed in all sections after the X-gal staining.

located nearby the membrane, which are characteristic of glomus cells in situ (Fig. 3I), were not observed in transplanted glomus cells, suggesting that, after denervation, there is a progressive decrease in the number of synaptic-like clustering of catecholaminergic secretory vesicles. Indeed, in glomus cells examined only $15 \mathrm{~d}$ after graft- ing, the dense-core vesicles appeared already dispersed over the cytosol (Fig. 4G).

Several authors have suggested that striatal reinnervation could be either induced simply by brain injury or gliosis (Ho and Blum, 1997; Song and Haber, 2000) or a consequence of nonspecific tissueinduced neurotrophism (Yurek and Sladek, 1990). It has also been postulated that macrophages activated after rupture of the brain-blood barrier in intracerebral grafts can produce neurotrophic factors and induce axonal sprouting (Batchelor et al., 1999). Although the lack of striatal reinnervation in the sham-operated parkinsonian animals (Espejo et al., 1998; Luquin et al., 1999; Hao et al., 2002; Toledo-Aral et al., 2003; Shukla et al., 2004) have already demonstrated the specificity of CB graft effects, we wondered whether GDNF is upregulated in brain parenchyma or in macrophages after CB grafting and/or brain damage. To address this question, we performed CB (from 1- to 2-month-old wildtype donors) or sham transplants in host heterozygous GDNF/lacZ animals (2-3 months old). Figure $5 A$ shows a large intrastriatal CB transplant with numerous glomeruli of immunostained TH-positive glomus cells. The typical blue X-gal deposits in the host ipsilateral striatum are marked by arrowheads. Note that these deposits do not accumulate in the proximity of the graft and that their appearance and density were similar in the contralateral striatum (Fig. 5B). No indication of GDNF expression were seen within cells in the substantia nigra of either sham-operated or CB-transplanted animals. These observations indicate that the $\mathrm{CB}$ transplant did not induce GDNF upregulation in the host nigrostriatal brain parenchyma. In shamoperated heterozygous GDNF/lacZ animals, abundant macrophages with the characteristic bright yellowish color were often seen along the needle tract (Fig. 5C, large arrows). In none of the animals studied $(n=3)$ did these macrophages (belonging to the host brain) show any sign of GDNF expression, whereas X-gal deposits were clearly observed in the neighboring striatum (Fig. 5C, small arrowheads). These results strongly suggest that striatal GDNF production is not significantly upregulated after $\mathrm{CB}$ grafting and that brain injury does not induce by itself an obvious increase in GDNF production by either macrophages or parenchymal brain cells.

GDNF expression in CB of aged and parkinsonian animals Autotransplantation of $\mathrm{CB}$ tissue produces notable clinical recovery in some PD patients, but it has little effect in others (Arjona et al., 2003). The variables that determine the clinical out- 
A

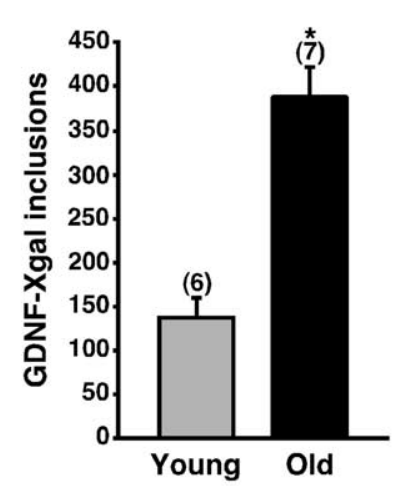

C

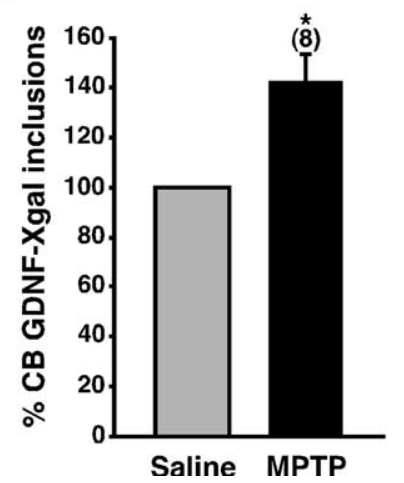

B

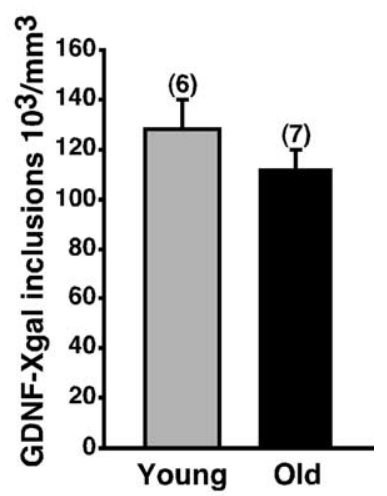

D

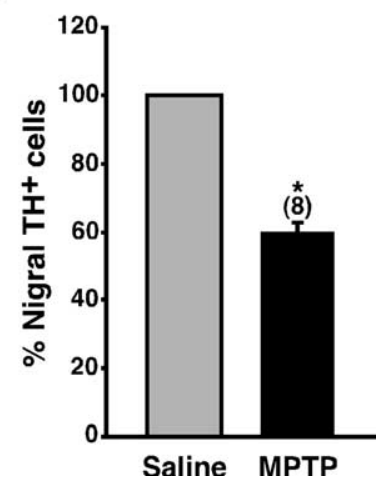

Figure 6. Maintenance of CB GDNF expression in aged and parkinsonian mice. $A$, Increase of GDNF expression (ordinate; estimated by the number of X-gal deposits per (B) in old heterozygous GDNF/lacZ mice (13-17.5 months of age) compared with young adults ( $2-4.5$ months of age). $\boldsymbol{B}$, Similar data as in $\boldsymbol{A}$ but normalized to the (B volume. $\boldsymbol{C}$, Increase of CB GDNF expression in chronic MPTP-treated mice compared with saline-treated littermates. In the same animals, the application of MPTP induced a clear reduction in the number of TH-positive nigral neurons (D). The number of experiments is indicated in parentheses. The statistical significance of differences among parameters was considered at ${ }^{*} p<0.05$ (see Materials and Methods).

come of CB autografts in PD are, at present, unclear, but patient age and advanced parkinsonism could be important limiting factors (Arjona et al., 2003). Therefore, we decided to evaluate in the rodent model whether the $\mathrm{CB}$ ability to synthesize GDNF is affected by age or the chronic administration of neurotoxins that destroy mesencephalic dopaminergic neurons. Interestingly, the average number of X-gal deposits per CB increased almost threefold in old mice (aged between 13 and 17.5 months) when compared with young adults (aged between 2 and 4.5 months) (Fig. 6A). This difference in GDNF expression was a consequence of the organ growth with age (Fig. $6 \mathrm{~B}$ ). We also investigated CB GDNF production in chronically MPTP-treated mice compared with sham-treated littermates. GDNF expression, as determined by the number of X-gal inclusions, was not reduced by MPTP (Fig. 6C). Surprisingly, chronic application of the toxin increased the number of X-gal deposits. MPTP-induced parkinsonism in the same animals was confirmed by the marked decreased in the number of dopaminergic nigra neurons (Fig. 6D). These experiments indicate that the activity of the CB GDNF promoter (and so the ability to express GDNF) is maintained intact along the mouse adult life. They also show that $\mathrm{CB}$ GDNF expression is resistant to neurotoxins capable of producing parkinsonism in mice and primates.

\section{Discussion}

Neurotrophic factors have become in recent years a therapeutic promise for brain repair in neurodegenerative diseases or after ischemia and trauma. Among these factors, GDNF has received special attention because of its potent effects on dopaminergic neurons (Lin et al., 1993). Exogenous GDNF also protects neurons from death after transient brain ischemia or in Huntington models (Araujo and Hilt, 1997; Miyazaki et al., 1999; Alberch et al., 2002), supports the survival of axotomized spinal and corticospinal motoneurons (Henderson et al., 1994; Giehl et al., 1998; Yuan et al., 2000), and retards toxic and hereditary Purkinje cell degeneration (McAlhany et al., 1997; Tolbert and Clark, 2003). In this article, we show that, besides being highly dopaminergic, $\mathrm{CB}$ glomus cells contain more GDNF than any other structure studied in the adult rodent and that the ability to synthesize GDNF is maintained in the CB of aged animals or after chronic MPTP treatment. Moreover, the production of high levels of GDNF is maintained in long-term intrastriatal CB grafts. Therefore, neuroprotection in $\mathrm{PD}$ and other pathological conditions could be achieved through delivery of GDNF by CB glomus cells transplanted in brain parenchyma or neuronal targets.

Most of our experiments were done with the GDNF/lacZ mouse, in which the activity of the GDNF promoter leads to the synthesis of $\beta$-galactosidase. Deposits of the enzyme are revealed by a simple histochemical (X-gal) reaction (Sánchez et al., 1996; Toledo-Aral et al., 2003). This technique sets a high threshold for the identification of GDNF-producing cells, because the formation of the characteristic X-gal cytosolic inclusion possibly requires high concentrations of the enzyme. Nevertheless, we found it to be an excellent and reproducible tool for the semiquantitative comparison of GDNF production among different tissues and a method with low susceptibility to experimental artifacts. Even in the CB, naturally expressed trophic factors are present at a level below that required for obvious detection with the classical immunocytochemical methods, which, at least in our hands, often yield false-positive results. It could be argued that the presence of cytosolic $\beta$-galactosidase deposits does not actually represent the activity of the GDNF promoter if, after being formed, they remain stable for long time periods. This does not seem to be the case because, in our heterozygous GDNF/lacZ animals, X-gal inclusions in cells of the neonatal retina disappeared after 1 or 2 weeks of postnatal life. The ability to express GDNF in adult glomus cells was also evident because $\mathrm{X}$-gal deposits increased in number with age and after MPTP treatment. Furthermore, we also observed that the number of X-gal deposits in freshly dissociated glomus cells is lower than in the in situ CBs, probably as a consequence of the dispersion trauma. However, the X-gal deposits reappear if the cells are allowed to recover in culture for $48 \mathrm{~h}$, thus indicating a relatively fast turnover of the $\beta$-galactosidase protein (data not shown). Moreover, GDNF expression in the $\mathrm{CB}$ and other tissues estimated with $\mathrm{X}$-gal staining in the lacZ mouse was in excellent agreement with the results obtained in adult rats, in which we measured the GDNF content and the amount released to the media using conventional and in situ ELISA immunodetection methods.

The dopaminergic nature of $\mathrm{CB}$ glomus cells and their ability to synthesize and release GDNF in large amounts make them optimally suited for cell therapy. Studies on animal models have shown that intracerebral application of exogenous GDNF can ameliorate parkinsonism. However, the amount of GDNF and the method of delivery are issues subjected to debate. Although other routes have been used, GDNF appears to yield best effects when delivered into the striatum, the target for nigral dopaminergic axons (Kirik et al., 2000). Among the different strategies 
for GDNF application are the intraparenchymal bolus injection of the protein (Tomac et al., 1995; Gash et al., 1996; Björklund et al., 1997; Rosenblad et al., 1998; Grondin et al., 2002) and the injection of engineered neural cell lines (Akerud et al., 2001) or replication-deficient viruses (Choi-Lundberg et al., 1997; Mandel et al., 1997; Kirik et al., 2000; Kordower et al., 2000; Bensadoun et al., 2003) expressing GDNF. These procedures are for safety reasons currently unpractical in humans. Monthly bolus injection of GDNF into the ventricles has been shown to be ineffective to ameliorate PD patients. Furthermore, numerous side effects were reported (Nutt et al., 2003), and there was no evidence of striatal dopaminergic reinnervation in a subject postmortem (Kordower et al., 1999). In contrast, direct and continuous infusion of GDNF into the putamen of PD patients has yielded significant clinical improvement in a safety trial (Gill et al., 2003). However, preliminary results of an independent double-blind placebo-controlled study, using the same method of GDNF delivery, are less favorable (Dingwell, 2004). Thus, continuous infusion of exogenous GDNF appears to depend on yet uncontrolled variables that influence the clinical outcome. Among these variables are the local changes of pressure, which could cause modifications unrelated with the neurotrophic effect of the protein, or the amount of GDNF being released, because it is known that excessive striatal GDNF expression produces downregulation of $\mathrm{TH}$ and aberrant axonal sprouting in downstream brain areas (Georgievska et al., 2002; Rosenblad et al., 2003). Intrastriatal grafting of CB tissue has been shown to produce notable dopaminergic reinnervation and behavioral recovery in parkinsonian rats (Espejo et al., 1998; Hao et al., 2002; Toledo-Aral et al., 2002, 2003; Shukla et al., 2004) and monkeys (Luquin et al., 1999). In rodents, CB grafts are maintained stable, with metabolically active dopamine- and GDNF-producing glomus cells for the entire animal lifespan. Therefore, glomus cells are ideal candidates to be used as biological pumps for the controlled endogenous release of GDNF and probably other trophic factors with unique synergistic actions. In fact, $\mathrm{CB}$ tissue contains BDNF (Erickson et al., 2001), and CB grafting has also been shown to reduce neuronal death in an acute rat stroke model (Yu et al., 2004). A limitation for the clinical use of glomus cell autotransplants in PD might be the small size of the $\mathrm{CB}$, which probably synthesizes less GDNF than is necessary for advanced PD patients (Arjona et al., 2003). However, this could be circumvented by the generation of glomus cell-like elements using adult stem cells or precursors administered at earlier stages of the disease.

From a physiological viewpoint, it is rather interesting that, among the cells of the sympathoadrenal lineage studied in adult rodents, glomus cells are those with higher capacity of GDNF synthesis. The level of GDNF expression in the CB appears to be also much higher than in the brain areas or paraneural tissues in which the trophic factor has been detected (Choi-Lundberg and Bohn, 1995; Trupp et al., 1995, 1997; Pochon et al., 1997). So, an obvious question that arises relates to the functional role of GDNF in the CB. Although the answer to this question is outside the scope of this paper, it is worth mentioning that GDNF is upregulated in response to brain toxic or ischemic damage (Schmidt-Kastner et al., 1994; Abe and Hayashi, 1997; Hida et al., 2003). We also shown that chronic systemic application of MPTP, sufficient to produce destruction of $\mathrm{SN}$ neurons, induces GDNF expression in glomus cells. Therefore, a plausible hypothesis is that, in glomus cells adapted to high environmental oxygen tensions in physiological conditions, the autocrine or paracrine action of trophic factors, as GDNF, is necessary to protect from oxidative stress.

Another interesting observation in our work relates to the possible activation of nonspecific sources of GDNF after brain injury. It has been suggested that dopaminergic striatal axonal sprouting can be induced either by brain injury and reactive astrocytes (Ho and Blum, 1997; Song and Haber, 2000) or by macrophage and microglia activation (Batchelor et al., 1999). Although expression of small amounts of GDNF by these cells cannot be discarded, our experiments using the GDNF/lacZ mouse clearly indicate that production of GDNF by host cells (astrocytes, microglia, or macrophages) is below the resolution of the X-gal detection method and clearly present in the $\mathrm{CB}$ tissue grafted into the striatum.

In conclusion, dopaminergic $\mathrm{CB}$ glomus cells are the elements studied with the higher capacity to produce GDNF in the adult rodent. This striking property is stably maintained after transplantation into the striatum. The clinical applicability of glomus cells to treat PD and possibly other neuropathological conditions should receive serious attention because they are, in principle, ideal devices for the endogenous long-term delivery of trophic factors in the brain parenchyma.

\section{References}

Abe K, Hayashi T (1997) Expression of the glial cell line-derived neurotrophic factor gene in rat brain after transient MCA occlusion. Brain Res 776:230-234.

Akerud P, Canals JM, Snyder EY, Arenas E (2001) Neuroprotection through delivery of glial cell line-derived neurotrophic factor by neural stem cells in a mouse model of Parkinson's disease. J Neurosci 21:8108-8118.

Alberch J, Perez-Navarro E, Canals JM (2002) Neuroprotection by neurotrophins and GDNF family members in the excitotoxic model of Huntington's disease. Brain Res Bull 57:817-822.

Araujo DM, Hilt DC (1997) Glial cell line-derived neurotrophic factor attenuates the excitotoxin-induced behavioral and neurochemical deficits in a rodent model of Huntington's disease. Neuroscience 81:1099-1110.

Arjona V, Minguez-Castellanos A, Montoro RJ, Ortega A, Escamilla F, Toledo-Aral JJ, Pardal R, Mendez-Ferrer S, Martin JM, Perez M, Katati MJ, Valencia E, Garcia T, Lopez-Barneo J (2003) Autotransplantation of human carotid body cell aggregates for treatment of Parkinson's disease. Neurosurgery 53:321-330.

Balkowiec A, Katz DM (2000) Activity-dependent release of endogenous brain-derived neurotrophic factor from primary sensory neurons detected by ELISA in situ. J Neurosci 20:7417-7423.

Batchelor PE, Liberatore GT, Wong JY, Porritt MJ, Frerichs F, Donnan GA, Howells DW (1999) Activated macrophages and microglia induce dopaminergic sprouting in the injured striatum and express brain-derived neurotrophic factor and glial cell line-derived neurotrophic factor. J Neurosci 19:1708-1716.

Bensadoun JC, Pereira de Almeida L, Fine EG, Tseng JL, Deglon N, Aebischer P (2003) Comparative study of GDNF delivery systems for the CNS: polymer rods, encapsulated cells, and lentiviral vectors. J Control Release 87:107-115.

Björklund A, Rosenblad C, Winkler C, Kirik D (1997) Studies on neuroprotective and regenerative effects of GDNF in a partial lesion model of Parkinson's disease. Neurobiol Dis 4:186-200.

Bohn MC, Cupit L, Marciano F, Gash DM (1987) Adrenal medulla grafts enhance recovery of striatal dopaminergic fibers. Science 237:913-916.

Choi-Lundberg DL, Bohn MC (1995) Ontogeny and distribution of glial cell line-derived neurotrophic factor (GDNF) mRNA in rat. Dev Brain Res 16:80-88.

Choi-Lundberg DL, Lin Q, Chang YN, Chiang YL, Hay CM, Mohajeri H, Davidson BL, Bohn MC (1997) Dopaminergic neurons protected from degeneration by GDNF gene therapy. Science 275:838-841.

DeFelipe J, Fairén A (1982) A type of basket cell in superficial layers of the cat visual cortex. A Golgi-electron microscope study. Brain Res 244:9-16

Dingwell A (2004) Neurotrophic factor frustration. BioCentury A10.

Erickson JT, Brosenitsch TA, Katz DM (2001) Brain-derived neurotrophic factor and glial cell line-derived neurotrophic factor are required simultaneously for survival of dopaminergic primary sensory neurons in vivo. J Neurosci 21:581-589.

Espejo EF, Montoro RJ, Armengol JA, Lopez-Barneo J (1998) Cellular and functional recovery of Parkinsonian rats after intrastriatal transplantation of carotid-body cell aggregates. Neuron 20:197-206.

Espejo EF, Gonzalez-Albo MC, Moraes JP, El Banoua F, Flores JA, Caraballo 
I (2001) Functional regeneration in a rat Parkinson's model after intrastriatal grafts of glial cell line-derived neurotrophic factor and transforming growth factor betal-expressing extra-adrenal chromaffin cells of the Zuckerkandl's organ. J Neurosci 21:9888-9895.

Gash DM, Zhang Z, Ovadia A, Cass WA, Yi A, Simmerman L, Russell D, Martin D, Lapchak PA, Collins F, Hoffer BJ, Gerhardt GA (1996) Functional recovery in parkinsonian monkeys treated with GDNF. Nature 380:252-255.

Georgievska B, Kirik D, Bjorklund A (2002) Aberrant sprouting and downregulation of tyrosine hydroxylase in lesioned nigrostriatal dopamine neurons induced by long-lasting overexpression of glial cell line derived neurotrophic factor in the striatum by lentiviral gene transfer. Exp Neurol 177:461-474.

Giehl KM, Schutte A, Mestres P, Yan Q (1998) The survival-promoting effect of glial cell line-derived neurotrophic factor on axotomized corticospinal neurons in vivo is mediated by an endogenous brain-derived neurotrophic factor mechanism. J Neurosci 18:7351-7360.

Gill SS, Patel NK, Hotton GR, O'Sullivan K, McCarter R, Bunnage M, Brooks DJ, Svendsen CN, Heywood P (2003) Direct brain infusion of glial cell linederived neurotrophic factor in Parkinson disease. Nat Med 9:589-595.

Grondin R, Zhang Z, Yi A, Cass WA, Maswood N, Andersen AH, Elsberry DD, Klein MC, Gerhardt GA, Gash DM (2002) Chronic, controlled GDNF infusion promotes structural and functional recovery in advanced parkinsonian monkeys. Brain 125:2191-2201.

Hao G, Yao Y, Wang J, Zhang L, Viroonchatapan N, Wang ZZ (2002) Intrastriatal grafting of glomus cells ameliorates behavioral defects of Parkinsonian rats. Physiol Behav 77:519-525.

Henderson CE, Phillips HS, Pollock RA, Davies AM, Lemeulle C, Armanini M, Simmons L, Moffet B, Vandlen RA, Simpson LC, Moffet B, Vandlen RA, Kolatsos VE, Rosenthal A (1994) GDNF: a potent survival factor for motoneurons present in peripheral nerve and muscle. Science 266:1062-1064.

Hida H, Jung CG, Wu CZ, Kim HJ, Kodama Y, Masuda T, Nishino H (2003) Pleiotrophin exhibits a trophic effect on survival of dopaminergic neurons in vitro. Eur J Neurosci 17:2127-2134.

Ho A, Blum M (1997) Regulation of astroglial-derived dopaminergic neurotrophic factors by interleukin-1 beta in the striatum of young and middle-aged mice. Exp Neurol 148:348-359.

Itakura T, Kamei I, Nakai K, Naka Y, Nakakita K, Imai H, Komai N (1988) Autotransplantation of the superior cervical ganglion into the brain. A possible therapy for Parkinson's disease. J Neurosurg 68:955-959.

Kirik D, Rosenblad C, Bjorklund A, Mandel RJ (2000) Long-term rAAVmediated gene transfer of GDNF in the rat Parkinson's model: intrastriatal but not intranigral transduction promotes functional regeneration in the lesioned nigrostriatal system. J Neurosci 20:4686-4700.

Kirik D, Georgievska B, Bjorklund A (2004) Localized striatal delivery of GDNF as a treatment for Parkinson disease. Nat Neurosci 7:105-110.

Kordower JH, Palfi S, Chen EY, Ma SY, Sendera T, Cochran EJ, Cochran EJ, Mufson EJ, Penn R, Goetz CG, Comella CD (1999) Clinicopathological findings following intraventricular glial-derived neurotrophic factor treatment in a patient with Parkinson's disease. Ann Neurol 46:419-424.

Kordower JH, Emborg ME, Bloch J, Ma SY, Chu Y, Leventhal L, McBride J, Chen EY, Palfi S, Roitberg BZ, Brown WD, Holden JE, Pyzalsky R, Taylor MD, Carvey P, Ling Z, Trono D, Hantraye P, Deglon N, Aebischer P (2000) Neurodegeneration prevented by lentiviral vector delivery of GDNF in primate models of Parkinson's disease. Science 290:767-773.

Lin LF, Doherty DH, Lile JD, Bektesh S, Collins F (1993) GDNF: a glial cell line-derived neurotrophic factor for midbrain dopaminergic neurons. Science 260:1130-1132.

Lipton JW, Ling Z, Vu TQ, Robie HC, Mangan KP, Weese-Mayer DE, Carvey PM (1999) Prenatal cocaine exposure reduces glial cell line-derived neurotrophic factor (GDNF) in the striatum and the carotid body of the rat: implications for DA neurodevelopment. Dev Brain Res 118:231-235.

Lopez-Barneo J, Pardal R, Ortega-Saenz P (2001) Cellular mechanism of oxygen sensing. Annu Rev Physiol 63:259-287.

Luquin MR, Montoro RJ, Guillen J, Saldise L, Insausti R, Del Rio J, Lopez-Barneo J (1999) Recovery of chronic parkinsonian monkeys by autotransplants of carotid body cell aggregates into putamen. Neuron 22:743-750.

Mandel RJ, Spratt SK, Snyder RO, Leff SE (1997) Midbrain injection of recombinant adeno-associated virus encoding rat glial cell line-derived neurotrophic factor protects nigral neurons in a progressive 6-hydroxydopamine-induced degeneration model of Parkinson's disease in rats. Proc Natl Acad Sci USA 94:14083-140888.
McAlhany Jr RE, West JR, Miranda RC (1997) Glial-derived neurotrophic factor rescues calbindin-D28k-immunoreactive neurons in alcoholtreated cerebellar explant cultures. J Neurobiol 33:835-847.

Miyazaki H, Okuma Y, Fujii Y, Nagashima K, Nomura Y (1999) Glial cell line-derived neurotrophic factor protects against delayed neuronal death after transient forebrain ischemia in rats. Neuroscience 89:643-647.

Nosrat CA, Tomac A, Lindqvist E, Lindskog S, Humpel C, Stromberg I, Ebendal T, Hoffer BJ, Olson L (1996) Cellular expression of GDNF mRNA suggests multiple functions inside and outside the nervous system. Cell Tissue Res 286:191-207.

Nutt JG, Burchiel KJ, Comella CL, Jankovic J, Lang AE, Laws Jr ER, Lozano AM, Penn RD, Simpson Jr RK, Stacy M, Wooten GF, the ICV GDNF Study Group (2003) Randomized, double-blind trial of glial cell linederived neurotrophic factor (GDNF) in PD. Neurology 60:69-73.

Pochon NA, Menoud A, Tseng JL, Zurn AD, Aebischer P (1997) Neuronal GDNF expression in the adult rat nervous system identified by in situ hybridization. Eur J Neurosci 9:463-471.

Rosenblad C, Martinez-Serrano A, Bjorklund A (1998) Intrastriatal glial cell line-derived neurotrophic factor promotes sprouting of spared nigrostriatal dopaminergic afferents and induces recovery of function in a rat model of Parkinson's disease. Neuroscience 82:129-137.

Rosenblad C, Georgievska B, Kirik D (2003) Long-term striatal overexpression of GDNF selectively downregulates tyrosine hydroxylase in the intact nigrostriatal dopamine system. Eur J Neurosci 17:260-270.

Rosenthal A (1998) Auto transplants for Parkinson's disease? Neuron 20:169-172.

Sánchez MP, Silos-Santiago I, Frisen J, He B, Lira SA, Barbacid M (1996) Renal agenesis and the absence of enteric neurons in mice lacking GDNF. Nature 382:70-73.

Schmidt-Kastner R, Tomac A, Hoffer B, Bektesh S, Rosenzweig B, Olson L (1994) Glial cell-line derived neurotrophic factor (GDNF) mRNA upregulation in striatum and cortical areas after pilocarpine-induced status epilepticus in rats. Mol Brain Res 26:325-330.

Shukla S, Agrawal AK, Chaturvedi RK, Seth K, Srivastava N, Sinha C, Shukla Y, Khanna VK, Seth PK (2004) Co-transplantation of carotid body and ventral mesencephalic cells as an alternative approach towards functional restoration in 6-hydroxydopamine-lesioned rats: implications for Parkinson's disease. J Neurochem 91:274-284.

Song DD, Haber SN (2000) Striatal responses to partial dopaminergic lesion: evidence for compensatory sprouting. J Neurosci 20:5102-5114.

Tolbert DL, Clark BR (2003) GDNF and IGF-I trophic factors delay hereditary Purkinje cell degeneration and the progression of gait ataxia. Exp Neurol 183:205-219.

Toledo-Aral JJ, Brehm P, Halegoua S, Mandel G (1995) A single pulse of nerve growth factor triggers long-term neuronal excitability through sodium channel gene induction. Neuron 14:607-611.

Toledo-Aral JJ, Mendez-Ferrer S, Pardal R, Lopez-Barneo J (2002) Dopaminergic cells of the carotid body: physiological significance and possible therapeutic applications in Parkinson's disease. Brain Res Bull 57:847-853.

Toledo-Aral JJ, Mendez-Ferrer S, Pardal R, Echevarria M, Lopez-Barneo J (2003) Trophic restoration of the nigrostriatal dopaminergic pathway in long-term carotid body-grafted parkinsonian rats. J Neurosci 23:141-148.

Tomac A, Lindqvist E, Lin LFH, Ogren SO, Young D, Hoffer BJ, Olson L (1995) Protection and repair of the nigrostriatal dopaminergic system by GDNF in vivo. Nature 373:335-339.

Trupp M, Ryden M, Jornvall H, Funakoshi H, Timmusk T, Arenas E, Ibanez CF (1995) Peripheral expression and biological activities of GDNF, a new neurotrophic factor for avian and mammalian peripheral neurons. J Cell Biol 130:137-148.

Trupp M, Belluardo N, Funakoshi H, Ibanez CF (1997) Complementary and overlapping expression of glial cell line-derived neurotrophic factor (GDNF), c-ret proto-oncogene, and GDNF receptor- $\alpha$ indicates multiple mechanisms of trophic actions in the adult rat CNS. J Neurosci 17:3554-3567.

Yu G, Xu L, Hadman M, Hess DC, Borlongan CV (2004) Intracerebral transplantation of carotid body in rats with transient middle cerebral artery occlusion. Brain Res 1015:50-56.

Yuan Q, Wu W, So KF, Cheung AL, Prevette DM, Oppenheim RW (2000) Effects of neurotrophic factors on motoneuron survival following axonal injury in newborn rats. NeuroReport 11:2237-2241.

Yurek DM, Sladek JR (1990) Dopamine cell replacement: Parkinson's disease. Annu Rev Neurosci 13:415-440. 